\title{
Accounting Foundation Course Flipped Classroom Application in Higher Vocational Colleges Teaching
}

\author{
Guo Hao, Meng Xuqin, \\ Qinhuangdao Institude of Technology, Qinhuangdao, Hebei, China, 066100
}

Keywords: Flipped classroom; Class mode; Higher vocational colleges

\begin{abstract}
With the teaching application of flipped classroom practice, this paper analyzes the advantages and disadvantages of flipped classroom teaching, and summarizes how to apply flipped classroom teaching model to higher vocational colleges teaching. Through flipped classroom, improve Higher vocational colleges classroom atmosphere, as well as the relationship between teachers and students and the cultivation of comprehensive quality.

With the continuous development of information technology in modern society, traditional teaching model cannot adapt to the present education situation. Worldwide popular "flipped classroom", as a more innovative teaching mode, is gradually accepted and loved, and its main content is that teachers prepare courseware in advance, and students use the Internet in their spare time to study the courseware first, then the teachers and students have face-to-face communication in the classroom to complete teaching purpose and tasks. Compared with traditional curriculum, it has better innovation, and it also fundamentally changed traditional mode of teaching, which emphasizes students' main body responsibility in that students are the main body of flipped classroom in the whole learning process, and strengthens the communication between teachers and students, improves students' learning interest and strengthens the affection between teachers and students. For the traditional education teaching mode in our country, to integrate the world's more popular kind of teaching mode into the classroom, we must combine not only students' own characteristics, but also school site hardware measures. This article mainly discusses and studies "flipped classroom" teaching mode in the classroom of vocational colleges, and combine with the specific situation of the education in our country, and puts forward the author's own opinion on education reform.
\end{abstract}

\section{Flipped classroom teaching idea}

Flipped classroom, as a popular teaching mode in western countries today, has brought a broader range of response and buzz in the society. Flipped classroom is originated by an American, whose name is Salman khan. He founded khan academy, and readjusted imparting knowledge and knowledge structure, changed traditional teaching teacher-student relation, and reorganized class time also for the adjustment.

\section{The difference between flipped classroom and traditional classroom teaching}

We can see from the name that flipped classroom is to make the class order upside down. And the biggest difference between flipped classroom and traditional classroom teaching mode is that education and learning are separated, and the order of teaching and learning is exchanged. Traditional teaching mode is that teacher imparts knowledge first, then students learn, and flipped classroom teaching mode is just the opposite. Students learn the materials prior to the teachers' lesson, and then formal classroom learning begins. The teaching mode mainly contains two parts: preparation and class, and there's a big difference in teaching effect because of different order.

Traditional teaching mode is composed of teaching, learning new knowledge, review leant knowledge, homework and so on several parts, and these contents are mainly distributed "in class" and "after class" two time points. First part is mainly that teachers organize lectures in class, and then classroom interaction learning before revision of old knowledge. The after class section mainly is that teacher assigns homework, let the students consolidate learned new knowledge and 
ultimately achieve mastery of new knowledge and usage.

Flip teaching can divide the class into "before" and "in" class two parts. In the process of preparation before class, teacher reasonably organizes the new lesson according to knowledge situation of students in the class, and let the students study the lesson before class via the Internet. The teacher guides learning before class to avoid detours. Through the Internet, let students construct their own knowledge network, and in the course, complete and elaborate the difficult knowledge and problems in detail, and finally respond to the feedback of the student in the classroom. Teacher timely corrects according to student feedback, and constantly improve classroom teaching.

\section{The analysis of flipped classroom in China's education system}

\section{A. The status quo analysis of higher vocational education teaching}

Influenced by traditional teaching concept, education in our country is still based on the examination score for teaching effect. This kind of teaching mode is easy to ignore the development of students' comprehensive aspects of morality, intelligence and physique. In traditional teaching mode, teachers pay more attention to students' performance in class, and have strict limits on students' classroom atmosphere, which forms teacher centered teaching mode. Teachers focus on students' examination results, and ignore students' creativity and subjective initiative, which is easy to make students become "nerds". In later work life, they also will be very hard to get into society, which is unfavorable to the principle of national excellent talents. Traditional teaching mode is impacted by modern teaching mode, and the traditional model has not adapted to the development requirements of teaching mode in modern society. How to combine student's interest and teaching content and make effective transformation in teaching and learning practice have become the focus of concern in modern society. Traditional teaching mode of higher vocational education has been difficult to meet the needs of social development in the fierce competition of modern society. In order to change traditional "teacher-centered" teaching model, constantly adapt to social development trend, train comprehensive talents for the needs of country, the generation of flipped education will play a make-up- role.

$B$. The specific requirements of the talents cultivation in higher vocational colleges

As the birthplace of primary skill talents in our country, the cultivation of higher vocational colleges has always been the country's high attention. To cultivate high-quality technical talents is the specific requirements and hope of higher vocational colleges to satisfy the needs of the society, which is a concrete embodiment of knowledge into ability. Higher vocational colleges are given priority to practical ability, therefore, strengthen teaching reform and innovation and cultivate high-skilled talents are the absolute principle of development. To achieve such a request, we need to adjust teaching strategies in higher vocational colleges, change traditional teaching mode, take the specific situation of the students as a starting point, and finally realize the talents training goal.

\section{The integration of flipped classroom teaching mode and higher vocational education}

In view of traditional teaching mode in higher vocational colleges, combining with its own characteristics and basic conditions of colleges and universities development comprehensive factors, traditional teaching mode innovation is the tide of times development. In the teaching process of higher vocational education, no matter what kind of teaching form adopted, the ultimate goal is to let students learn knowledge, and put the knowledge into skills, and flipped classroom broke traditional concepts in traditional teaching, which takes the teacher as the center, and let students illustrate knowledge by themselves, which exercises the students' practical ability, so as to achieve the aim of training students. Schools can innovate in view of flipped classroom teaching method and their own circumstance, and find a suitable teaching way for their own development.

\section{The application analysis of flipped classroom in higher vocational education}

Because the teachers' relative strict control for students' classroom performance and students' 
classroom behavior in traditional teaching mode, plus students' own quality and accomplishment, personality, and so on, it is difficult to realize students' autonomous learning in local place, so it is not easy to promote personalized learning. Some students are not interested in theoretical courses, and it is difficult to achieve a more standard unification. Under the influence of Chinese traditional teaching pattern, some students are hard to change, and accustomed to the traditional way of teaching.

Combining flipped classroom learning mode with learning characteristics of higher vocational colleges, the author summarized the following points on how to integrate innovative flipped classroom learning mode with traditional teaching mode:

\section{A. Material preparation before class}

In the process of teaching, strengthen teaching resources preparation before class. In view of the traditional mode, teaching has self-study learning time. Teachers can make teaching video ready in the teaching process, and show the teaching video after school or on self-study play, so as to achieve teaching video lectures vanguard role. Video content can be either lecture teachers personally record, or can also be outstanding teaching resources from online collection. Pay attention to the choice when recording video, and the key is to let students learn knowledge, and to ensure that the content of the video "clean". Avoid the bad things which influence students' attention and prepare some small games to stimulate learning interest, etc. In "flipped classroom education" concrete implementation, teachers are bound to have more teaching time, and the use of the teaching time should be reasonable. While students are watching the video, we can let students watching video and do practical exercise at the same time. Teachers can solve the problem on site while accompanying students watch video in a timely manner. In practice, one-on-one tutoring can not only reduce the distance between teachers and students faster, but also can stimulate the learning enthusiasm of the students, in order to improve the classroom teaching requirements. And for those who are relatively disadvantaged, pay more attention to strengthen their support, and eventually make the class atmosphere rise to a new level.

\section{$B$. Pay attention to the transition of roles between teachers and students}

Swaps, pay attention to classroom teacher-student relationship, which is to focus students in classroom teaching. Teachers play a helper role, and divide the students into groups which enable students to participate in group discussion. Through personalized guidance study, it is beneficial to the development of relationship between teachers and students and tacit understanding. The closer the distance between teachers and students helps to improve the students' cognition and learning enthusiasm. Students can seek the answers to the problems in class so as to develop the students' ability and prevent and control the formation of students' introversion, which help students to form optimistic, cheerful personality. Teachers can also help the team set up according to the needs of the class. Help those who are disadvantaged and let students to have group discussions to solve the problems before class, and finally the teacher solve the problems of doubt in the whole class.

\section{Do maintenance work after class}

After class, feedback teaching information in time by questioning and in investigation form, continue to maintain and carry forward the students' satisfying teaching modes, and in view of the problems existing in teaching, adjust timely and correctly. Give full play of teaching resources.

\section{Seize the key point}

In order to effectively implement "flipped class", a lot of people put main energy in video production before class. In fact this is a mistake. Making video is important, but what is more important than making video is class arrangement. How to make students better able to enter learning state, better knowledge, and master the knowledge into part of their ability, are more important. In classroom, dialogue and discussions between classmate and teachers and students need teachers more detailed preparation and observation so as to really do it according to their aptitude education policy. 


\section{Conclusion}

In the teaching of higher vocational teaching mode, to ensure flipped classroom teaching mode used in teaching, we should also have several aspects: the hardware support to ensure the teaching in higher vocational colleges, release and check teaching information in time, which also relates to whether class teaching can be implemented effectively, and a larger influence on students learning after class. The teacher must reasonably control the teaching content and teaching methods, prevent and control teaching of out of control phenomenon. And teachers should have professional quality and professional ethics. Teachers should cultivate students' autonomous learning ability in teaching, because students' autonomous learning ability is one of the key factors for success or failure for flipped classroom teaching effect. Communicate with students after class and increase the affection between teachers and students. In order to effectively flip the orderly implementation of classroom teaching, we also need to make some corresponding regulation measures for students so as to better safeguard the order of the class.

There is no perfect teaching mode, in the process of teaching, only by constantly improving teaching mode, we can adapt to the changing of teaching content. In teaching, teaching method which promotes effective teaching in the teaching process is suitable for education reform tide, thus, in later study and teaching, keep pace with the Times, and constantly make effective innovation of existing things. Apply "flipped classroom" teaching model to the teaching of higher vocational education so as to constantly check "flipped classroom" teaching mode and teaching content.

\section{References}

[1] Pen Ning. Introduction to "flipped classroom" mode application in higher vocational education classroom [J]. Science Review, 2014, (24).

[2] YuYongkang, Jin Weiguo, Deng Xiaolong. "Electrotechnics" curriculum construction research and practice under the mode of "flipped classroom" [J]. Journal of Education and Teaching Research, 2014, 28 (7) : 78-80.

[3] Gu Yan. The application of "flipped classroom" teaching in higher vocational schools study [J]. Modern Enterprise Education, 2014, (22).

[4] Zhang Jinlei, Wang Ying, Zhang Baohui. Flipped classroom teaching mode study [J]. Journal of Distance Education, 2012, 30 (4): 46-51.

Guo Hao (1981), male (han), Hebei Qinhuangdao, master, lecturer, main research direction: economic management.

No. 90 Seaside Lian Feng North Road, Beidaihe, Qinhuangdao, Hebei 